\title{
Education in accident and emergency medicine for senior house officers: review and recommendations
}

\author{
Howard Rodenberg
}

Providing a notable educational experience in accident and emergency (A\&E) medicine is a major objective of any department which serves as a base for senior house officer (SHO) teaching. The positive impact of an $A \& E$ specialty training programme on non- $A \& E$ trainees has been well documented. ${ }^{12}$ Unfortunately, SHO instruction in A\&E suffers from a lack of agreement on what issues should be addressed, what forms of teaching ought to be used, and how to infuse educational vitality into $A \& E$ attachments. It is the intent of this paper to further the discussion towards an innovative educational philosophy and $A \& E$ core curriculum.

\section{The need for A\&E education}

There is clearly a role for the A\&E specialist in the education of SHOs. Burdick reviews both the needs and goals for undergraduate emergency medicine education. ${ }^{3}$ The need for $\mathrm{A} \& \mathrm{E}$ education is further driven by public expectations; one of these is a physician's ability to provide immediate care at the scene of injury or illness. Physicians who cannot or will not assist their fellows in times of urgent need fall below these ideals.

The need for specific A\&E training is dependent upon what material has been learned before house officers come to the A\&E. A Texas study indicates that while some $A \& E$ material is learned from other disciplines, there remains a unique core of knowledge." "War stories" exchanged between career $A \& E$ physicians often reflect the inability of senior staff in other disciplines to perform adequately in the $A \& E$; this reflects educational gaps dictated by the process of specialisation.

The British Association for Accident and Emergency Medicine (BAEM) has issued recommended SHO teaching standards. While the paper suggests reserved teaching sessions, situational instruction, and induction courses, it was written broadly and did not discuss educational theory or content. ${ }^{5}$

School of Clinical

Medicine,

Accident and

Emergency

Department,

Addenbrooke's

Hospital,

Cambridge CB2 2QQ

$\mathrm{H}$ Rodenberg

Correspondence to:

Howard Rodenberg MD

FACEP,

Medical Rescue

Medical Rescue
International Inc,

PO Box 91622 ,

Puckland Park 2006

Republic of South Africa. structure of these sessions is dictated by b the needs and resources of the department. Some departments further encourage SHO participation in advanced cardiac life support (ACLS), advanced trauma life support

\section{Current approaches}

The approach to SHO education varies
(ATLS), or other set courses concerned with acute care. Currently, no core curriculum exists in the United Kingdom to guide construction of either induction courses or weekly teaching sessions.

In departments short of senior staff and resources, service needs may obligate SHOs to forgo meaningful instruction. It has been suggested that optimum staffing dictates that there should be one SHO for every 5000 new patients who present to an A\&E each year. ${ }^{6}$ Institutions may lack even this basic level of coverage, greatly reducing the opportunities for education and, in turn, the odds of improving patient care.

A\&E curriculum: theoretical framework Any curriculum rests on specific educational philosophies and goals. An A\&E curriculum accepts the requirement to teach not only facts but also processes of $A \& E$ work. The practice of $A \& E$ is radically different from that of any other medical specialty. A\&E physicians work "backwards," accepting a brief assessment and providing immediate care rather than pursuing a prolonged diagnostic process and using narrowly focused interventions. This philosophy is best summed up in the adages that, "The patient defines the emergency," and, "Management is more important than diagnosis". The role of the emergency physician is to evaluate every patient for the presence of an immediate threat to life or limb. Should these conditions exist, it is the physician's responsibility to stabilise the patient and refer him for definitive care. Detailed knowledge of pathophysiology and therapeutics, while desirable for optimal care, is not required to achieve basic $A \& E$ goals. Comprehension of these ideas is key to the SHO's understanding of $A \& E$ medicine.

This practice paradigm suggests that the major intent of an $A \& E$ curriculum is to educate SHOs what not to do. The most important role for the $\mathrm{SHO}$ in $\mathrm{A} \& \mathrm{E}$ is preventing patient deterioration. Stated crudely, the primary goal of $\mathrm{A} \& \mathrm{E}$ education is to teach SHOs not to kill anyone. Similarly, SHOs should predominately be taught what they need to know, not what they might wish to know. Knowledge of the specific actions of a drug is always desirable, but not always necessary to know when and how to use it.

An A\&E curriculum must be symptom oriented. Patients come to A\&E departments with symptoms, not diagnoses. It is the job of 
A\&E staff to sort through complaints and identify emergency conditions, and teaching must reflect this reality.

A curriculum must be interactive and adaptable. Time must be reserved for senior $A \& E$ personnel to present cases (old or new) instructive to SHOs representing errors in care, exemplary efforts, specific clinical problems, or as a focus for discussion of departmental issues related to patient care. Case presentation conferences allow SHOs to discuss cases of particular interest to them. Senior feedback at these sessions provides expert review and fosters closer working interactions between staff. Mannikin and moulage practice sessions reinforce psychomotor skills under the guidance of senior personnel.

Finally, a curriculum should focus on topics unique to $A \& E$. Undeniably, much of $A \& E$ practice is comprised of knowledge derived from other specialties. Inclusion of these areas may be an unwarranted duplication of effort. Teaching programmes may also be adjusted to the likelihood of the SHO receiving situational instruction within the topic area. ${ }^{78}$

\section{Course content}

These assumptions dictate teaching methods, but only indirectly specify course content. Two views predominate on this subject. The first notes that the core work of the SHO is to preserve life until definitive care is provided. Therefore acute medical and surgical care must receive priority. The second proposes that SHOs primarily require knowledge of conditions they are most likely to see (excepting minor injuries).

The optimal mix lies between these extremes. An induction course should focus upon the time-critical components of care. Airway management, defibrillation, and wound care mandate detailed care in the first encounter. Bony and soft tissue injuries allow some margin for delay, as patients may be able to return to the department for re-evaluation without complication (assuming initial examination reveals no acute deficits and appropriate stabilisation is performed).

A proposed induction course should also include "soft" topics such as dealing with the difficult patient. SHOs will be subject to unique stressors as they assume their duties. Providing education in these areas both recognises these entities and builds support systems.

An A\&E curriculum is best divided into three sections. The "critical curriculum" contains topics SHOs must review before their first nights in the department, and takes the place of most current induction courses. "Core curriculum" represents instruction in high priority topics to be accomplished within the first two weeks of attachment. Remaining areas of import ("comprehensive curriculum") are integrated throughout the remaining months. These lectures are interspersed with case presentations and moulage sessions.

Each portion of the critical, core, and comprehensive curriculum should be linked with a reading selection. Selections should be chosen for brevity, relevance, and consistency with the educational philosophy of the program.

A suggested complete curriculum, as well as a background discussion paper, are available from the author.

\section{Methods of instruction}

Critical curriculum is best taught as a centralised programme for all SHOs within a regional referral pattern. In a centralised programme, the best teachers within a region can be selected. The centralised format also allows uniform dissemination of policies affecting $A \& E$ departments within a region.

Core curriculum is best taught at individual institutions, using a common "script". This allows educational objectives to be standardised while allowing staff at each facility to learn from one another. The remainder of topics are best taught by local consultants and will be guided by local interests.

Participation by SHOs in clinical audits are not part of this curriculum. Traditional audits often result in negative reinforcement; in contrast, SHOs require maximum positive input. If audits are to be used, they should be used only in a manner highlighting problems within the SHOs' capability to resolve.

A key debate concerns the specialty origin of instructors. Ideally, senior grade A\&E staff comprise the core group of instructors. Extensive use of specialty physicians has many drawbacks. Many do not understand the differences between $A \& E$ and specialty care, and may not be able to focus their knowledge upon the acute care setting.

A mix of the two knowledge bases is ideal. This may be achieved through sequential lecturing, in which a specialist presents a view followed by a second speaker who puts the issue into an $\mathrm{A} \& \mathrm{E}$ context. Conjoint lecturing, in which both $A \& E$ and specialist parties offer opinions in a friendly, adversarial format, may create the most interest and convey the most knowledge.

A related question arises from the recognition that not all staff are born instructors. Any scheme which centralises teaching does, to some extent, allow selection of the most optimal instructors. In any event, it clearly benefits all career grade staff to undertake a brief educational methodologies course upon assumption of their post. Alternatively, departments could commit funding a designated shared registrar or senior registrar $A \& E$ teaching post. Selection committees should be encouraged to accept such a post as an acceptable substitute for research when vetting for senior positions. Teachers must be consistently and regularly evaluated by learners and fellow instructors in order to maintain excellence. One study clearly illustrates a negative correlation between self reporting of teaching behaviours and actual performance of faculty members. ${ }^{9}$

A dichotomy also exists between talking and teaching. Bedside teaching has been the foundation of medical instruction for centuries. However, SHOs exposed to extensive 
lecturing often complain their education suffers because seniors do not work on the shop floor demonstrating practical applications. Decreased administrative workloads and increased funding to allow expansion of senior staff grades and shop floor hours is required to allow this practical "hands on" instruction to occur. The best teaching is interactive; adults learn best when confronted with a "need to know." As physicians deal with patients on a practical level, it makes sense to encourage senior clinical sessions focusing on teaching real-time patient assessment and care.

Finally, any attempt at teaching is doomed to failure if the instructor fails as a motivator and role model. Teaching is a public relations exercise. The most knowledgeable physician is often not the best teacher. The one who knows less, but conveys excitement at what he does know and marvels at what he does not is likely the ideal instructor candidate.

\section{Evaluation and testing}

Studies have explored issues relating to the evaluation of rotating house officers in A\&E. Ten Eyck and Maclean found that evaluations are limited by their retrospective nature and propose a computer model which requests one aspect of a trainee's performance be recorded after each clinical session. ${ }^{10}$ One novel approach asks staff nurses to participate in trainee evaluations. The results of these evaluations are noted to improve behavioural interactions between trainees and nursing staff. ${ }^{11}$

Feedback to SHOs not only enhances performance but contribute to team building within the department. It seems reasonable that every two months a member of the $A \& E$ staff meet with each SHO to inquire as to their wellbeing and whether their professional expectations are being met. SHO self evaluations and clinical observations serve as evaluative tools. These meetings are also an opportunity for giving notice of deficiencies and offering opportunities for improvement. Documentation of these meetings is crucial, especially when poor evaluations are given or disciplinary action is considered.

Subjective evaluation of the course must also occur. Lectures should be evaluated at the time of presentation, and those dealing with major topics be reassessed at the end of the attachment to clarify their value.

Testing of $A \& E$ trainees is controversial. The examination structure in the United Kingdom is designed to fail candidates on a percentage basis irrespective of the quality of the candidate group. As such, SHOs look upon examinations as an opportunity to exhibit failure. In fact, competent SHOs who perform poorly during assessment bring shame only upon the ethos of the testing establishment and the educational programme that has prepared them for evaluation.

Attempts must be made to separate SHO assessments as measures of progress from traditional qualifying examinations. This can be done by eliminating "pass-fail" barriers and performing sequential assessments during the rotation, using guided instruction to remedy deficiencies. SHOs have a right to know the specific items of skill and knowledge upon which they will be assessed, and teaching programmes have a responsibility to ensure that this material is not only provided, but taught and learned.

A key issue in determining the optimal means of assessment is how to make examinations as objective as possible. Well written multiple choice questions (MCQs) are the "gold standard" of objectivity, but do not provide an opportunity to evaluate thought processes or clinical skills. Short answers and verbal quizzes have a place, but only when they have a definitive answer to avoid variability in clinical practices, interpretation of responses, and non-conformity in writing and speaking skills. Skill testing may also be used. In this case, assessment must be based on the performance of an undisputed "critical action" and not on the efficacy, confidence, or agility of the trainee being assessed.

\section{Enhanced supervision}

Appropriate supervision of SHOs is key to providing an adequate educational experience. Senior grade A\&E staff are not exposed to all patients who attend the department. However, studies have documented benefits to senior staff review of all cases seen in the A\&E. An American study showed that $37 \%$ of patients had modifications of care when all patients seen by second year emergency medicine residents were reviewed by attending (consultant) physicians; and a survey of US academic medical centres found that $95 \%$ of faculty and $71 \%$ of residents agree that 24 hour attending coverage improves the quality of patient care. ${ }^{12} 13$

The East Anglia Regional Training Group recognised the benefits of expanded senior coverage when they noted that there should be evening shopfloor coverage by a senior until at least midnight and a consultant or other senior grade staff as the primary on call contact after this time.14 While these schemes may seem financially impractical, the potential closure of smaller departments and the increased efficiency of supervised care may make this a viable option. Departments with multiple grades of career staff have already been able to achieve extended hours of shopfloor coverage on a "shift work" basis.

\section{Implementation}

Implementation of any new educational plan cannot happen overnight. In general, didactic components will be easier to implement than changes affecting departmental structure (that is, enhanced senior staffing). In addition, many well staffed departments are currently conducting active teaching programmes, and require minimal effort to shift to a new design.

SHOs may work in institutions where there are no dedicated $A \& E$ consultants or where they are geographically isolated, placing extreme burdens upon scarce A\&E staff. All 
SHOs within a city or region may unite for compressed induction courses and teaching sessions. An alternative uses interactive video technology to allow students and house officers to "attend" lectures from afar. A third option is the use of standardised videotapes which can be viewed at the leisure of the SHO. While this scheme is most economical, it assumes a large degree of self motivation. The ideal means for educating SHOs in smaller facilities may well be a combination of these methods. Computers can also be used to implement parts of the training curriculum. Computer programs are interactive and self paced, and have been validated as $A \& E$ educators. 15 However, computers should rarely represent the first line of instruction, as they cannot reproduce the crucial interchange between students and preceptors.

The greatest obstacle to progress, however, will be the current image of the specialty of $A \& E$. It is undeniable that the vast majority of senior physicians, deans, and policy makers do not understand the goals, methodologies, or clinical requirements of the specialty. Not long ago there simply were no A\&E consultants. Most doctors in training (and all surgeons) served time as casualty officers, and the assumption persists that "because everyone did it, anybody can." It is therefore not considered an area of medical specialisation or import, and not a priority for the expenditure of attention or resources (though it does serve as a focus for complaints). The current generation of policy makers matured similarly in the absence of $\mathrm{A} \& \mathrm{E}$ and emergency medical services advocates, and shares an unintentional ignorance of $A \& E$ care. Even though $A \& E$ services are now recognised as essential, and are featured in the Patient's Charter hospital, old impressions still dictate current perceptions. While it may require a generational change to correct these attitudes, there remain clear objective advantages to enhancing $A \& E$ operations.

Will there be additional costs associated with this scheme? The answer is a qualified yes. Time and funding must be made available for SHOs to attend course work and to free staff to participate in teaching and work additional clinical hours. Funding will also be required to produce educational resources and pay support staff. Postgraduate deans must stress to NHS trusts the need for funding to allow enhanced clinical coverage and educational off-service time.

In the short term, costs will rise. The increase, however, must be weighed against the increased time efficiency, more focused use of $A \& E$ resources, and improved attitudes of A\&E SHOs. All of these factors will result in improved patient care and closer adherence to Patient's Charter standards. Improved patient care leads to improved patient satisfaction, a critical criterion in these days of mounting public criticism of health services. A small commitment to educational programming yields a host of benefits.

A final question concerns the impact of educational schemes on SHO recruitment. It has been strongly suggested that institutions with poor teaching programmes can only recruit poor SHOs. It must be acknowledged that SHO jobs are selected on a combination of factors including culture, climate, perceptions of senior staff, and career training requirements. However, jobs with the best reputations are often those where a heightened focus on education forces seniors staff to attain higher levels of excellence in teaching, research, and patient care. This educational commitment, when linked to strong senior support for the efforts of house officers and a significant presence on the shopfloor, makes jobs desirable and lessens recruitment woes.

\section{Conclusions}

SHO training in accident and emergency medicine in the United Kingdom currently lacks consistency of both content and methods. In this report I have reviewed the current status of educational programmes for these young physicians and made suggestions for their improvement. It is hoped that this work will act as a catalyst for further discussions between senior consultants in accident and emergency medicine at all levels.

\section{Summary}

Education of SHOs during A\&E attachments remains problematic. Teaching programmes suffer from the lack of a clear educational vision and the resources required to enhance training while maintaining service. Divisions within and without the specialty also hamper these efforts. This article outlines a theoretic framework to guide $\mathrm{A} \& \mathrm{E}$ education for SHOs, and explores its ramifications for course content, teaching methods, implementation, and evaluation. This framework can act as a template upon which to build programmes tailored to the needs of both the $A \& E$ department and the SHO.

1 Schwab RA, Kuhlmann TP, Fan YH Impact of an emergency medicine residency program on rotator's emergency medicine residency program on rotator's emergency

2 Gallagher EJ, Goldfrank LR, Anderson GV, et al. Role of emergency medicine residency programs in determining emergency medicine career choice among medical students. Ann Emerg Med 1994;23:1062-7.

3 Burdick WP. Emergency medicine's role in the education of medical students: directions for change. Ann Emerg Med 1991;20:688-91.

4 Binder L, Scragg W, Chappell J, et al. Augmenting the critical care data base of junior medical students with an emergency medicine lecture curriculum: a controlled study. $\mathcal{F}$ Emerg Med 1990;8:211-4.

5 Academic Committee, British Association for Accident and Emergency Medicine. Recommended teaching standards in accident and emergency departments. London: BAEM 1991

6 Royal College of Surgeons of England. Standards for SHO training. London: RCSE, 1987.

Langdorf MI, Strange G, Macneil P. Computerized tracking of emergency medicine resident clinical experience. Ann Emerg Med 1990;19:764 73

8 De Lorenzo RA, Geehr EC. Analyzing clinical case distributions to improve an emergency medicine clerkdistributions to improve an emergency

9 Hartman SL, Nelson MS. What we say and what we do: self-reported teaching behavior versus performances in self-reported teaching behavior versus performances in
written simulations among medical school faculty. Acad Med 1992;67:522-7.

10 Ten Eyck RP, Maclean TA. Improving the quality of emergency medicine rotation/clerkship evaluations. $A m \mathcal{F}$ Emerg Med 1994;12:113-7.

11 Tintinalli J. Evaluation of emergency medicine residents by nurses. Acad Med 1989;54:49-50. 
12 Sacchetti A, Carraccio C, Harris RH. Resident management of emergency department patients: is closer attending supervision needed? Ann Emerg Med 1992;21:749-52.

13 Henneman PL, Hockberger RS, Chiu C. Attending coverage in academic emergency medicine: a national survey. Ann Emerg Med 1989;18:34-41.
14 East Anglia Regional Training Group. SHO training and supervision in accident and emergency medicine. December, 1994.

15 Papa FI, Meyer S. A computer-assisted learning tool designed to improve clinical problem-solving skills. Ann Emerg Med 1989;18:269-73.

\section{FACULTY OF ACCIDENT AND EMERGENCY MEDICINE}

\section{Consultant Appointments January-April 1996}

\section{Name}

Mr B Al-Wakeel

Mr J Binchy

Dr T Brown

Mr C J Cahill

Dr S Crowder

Mr S Durham

Dr R J Evans

Mr Adrian Fogarty

Mr V Gautam

Mr R Goel

Ms R Johnson

Dr S I Kitchen

Ms P Longstaff

Dr O Marzouk

Ms F Moore

Mr S W Payne

Dr B Phillips

Mr F Richardson

Mr B Sinnoff

Mr A Soorma

Mr S Suleman

Mr B Tesfayohannes

Mr S Wadhani

\section{Post}

Consultant in $\mathrm{A} \& \mathrm{E}$

Consultant in A \& E

Consultant in A \& E

Consultant in A \& E

Consultant in $\mathrm{A} \& \mathrm{E}$

Consultant in $\mathrm{A} \& \mathrm{E}$

Consultant in A \& E

Consultant in A \& E

Consultant in A \& E

Consultant in A \& E

Consultant in A \& E

Consultant in $\mathrm{A} \& \mathrm{E}$

Consultant in A \& $\mathrm{E}$

Consultant in A \& E

Consultant in A \& E

Consultant in $\mathrm{A} \& \mathrm{E}$

Consultant in A \& E

Consultant in A \& E

Consultant in A \& E

Consultant in A \& E

Consultant in A \& E

Consultant in A \& E

Consultant in A \& $\mathrm{E}$

\section{Hospital}

Kingston Hospital

Derriford Hospital, Plymouth

St Helens and Knowsley

Queen Alexandra Hospital,

Cosham

Warrington Hospital

Royal Lancaster Infirmary

Cardiff Royal Infirmary

The Royal Free Hospital

Queen Elizabeth Hospital,

Welwyn Garden City

Kingston Hospital

Worcester Royal Infirmary

Scunthorpe and Goole Hospitals

Chelsea and Westminster

Alder Hey Children's Hospital,

Liverpool

Charing Cross Hospital

Ealing Hospital

Alder Hey Children's Hospital,

Liverpool

Glan Hafren Trust

Downshire Hospital, Northern

Ireland

Newham Healthcare Trust

St Helier NHS Trust, Carshalton

Northern General, Sheffield

North Tees General Hospital 